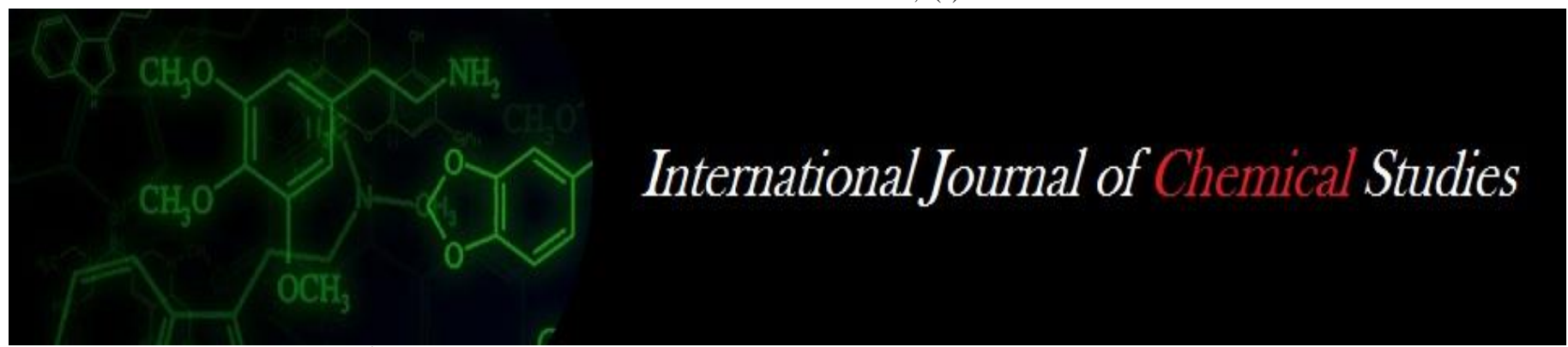

P-ISSN: 2349-8528

E-ISSN: 2321-4902

www.chemijournal.com

IJCS 2020; 8(3): 1968-1973

(C) 2020 IJCS

Received: 17-03-2020

Accepted: 19-04-2020

\section{Anant Tamang}

Department of Horticulture, MS

Swaminathan School of

Agriculture, Centurion

University of Technology and

Management, R Sitapur,

Gajapati, Odisha, India

\section{Venkata Satish Kuchi}

Department of Horticulture, MS

Swaminathan School of

Agriculture, Centurion

University of Technology and

Management, R Sitapur

Gajapati, Odisha, India

\section{BC Das}

Department of fruits and orchard management, Faculty of

Horticulture, BCKV, Mohanpur,

Nadia, West Bengal, India

\section{Soumik Ray}

Deparment of Economics and

Agricultural Statistics, MS

Swaminathan School of

Agriculture, Centurion

University of Technology and

Management, R Sitapur,

Gajapati, Odisha, India
Corresponding Author:

Anant Tamang

Department of Horticulture, MS

Swaminathan School of

Agriculture, Centurion

University of Technology and

Management, R Sitapur,

Gajapati, Odisha, India

\section{Genetic diversity characterization of Wood apple (Feronia sps.) for identification of superior genotypes}

\author{
Anant Tamang, Venkata Satish Kuchi, BC Das and Soumik Ray
}

DOI: $\underline{\text { htps://doi.org/10.22271/chemi.2020.v8.i3aa.9493 }}$

\begin{abstract}
Wood apple fruit is a hard shelled many seeded berry with its pinkish brown aromatic sour - sweet pulp being the edible portion. Total eleven (11) numbers of wood apple plants were stratified from different agroclimatic zones of West Bengal depending on availability of fruit crop and convenience of the study at Bidhan Chandra Krishi Viswavidyalaya, Mohanpur, Nadia, West Bengal during the years 2013-2015. Under the observation for characterization, the plant physical parameters has been analyzed with the help of Biodiversity International Tropical Fruit Descriptor (NBPGR) and so for preliminary evaluation, fruit physical parameters and fruit biochemical parameters has been analyzed. During the course of survey the tree age of wood apple varied from 15yrs to above 40yrs in age at different germplasm in which the height and trunk girth varied from $10 \mathrm{~m}$ to above $20 \mathrm{~m}$ and $88.2 \mathrm{~cm}$ to $157.4 \mathrm{~cm}$. Branching pattern and crown shape was observed to be irregular in all the accessions whereas, tree growth habit varied from erect to spreading type. Leaf characters in wood apple reveals obovate leaf blade shape, obtuse to retuse leaf apex, cuneate leaf base, odd pinnate leaf orientation and pinnate leaf venation. Length of the leaf blade ranges from $3.05 \mathrm{~cm}$ to $4.12 \mathrm{~cm}$ and breadth varies from $1.06 \mathrm{~cm}$ to $3.08 \mathrm{~cm}$. Maximum fruit length was recorded in ACC-8 $(8.04 \mathrm{~cm})$ and breadth of $7.96 \mathrm{~cm}$ in ACC-6. Maximum fruit weight $(306.02 \mathrm{~g})$, peel weight (73.68 $\mathrm{g}$ ) and number of seeds (28.42) was from the ACC-4. Maximum total sugar 28.57 $\mathrm{mg} / 100 \mathrm{gm}$ pulp (ACC-1), reducing sugar $13.88 \mathrm{mg} / 100 \mathrm{gm}$ (ACC-4), acidity $1.77 \mathrm{mg} / 100 \mathrm{gm}$ (ACC-5) and Vit. C $102.04 \mathrm{mg} / 100 \mathrm{gm}$ (ACC-2) has been recorded. Average linkage technique clustering when applied on squared Euclidean distance matrix a total of 6 clusters were formed for plant physical parameters, a total of 7 clusters were formed for fruit physical parameters and a total of 6 clusters were formed for fruit biochemical parameters.
\end{abstract}

Keywords: Wood apple, Branching pattern, Fruit parameters, Leaf characters

\section{Introduction}

The wood apple syns. F. elephantum Correa; Limonia acidissima L.; Schinus limonia L.) is the only species of its genus, in the family Rutaceae with $2 n=18$ chromosomes. Wood apple is native and common in the wild dry plains of India and Ceylon and cultivated along roads and edges of fields and occasionally in orchards. The fruit is a hard shelled many seeded berry with its pinkish brown aromatic sour - sweet pulp being the edible portion. Edible full ripe pulp contains, on an average, $69.5 \%$ moisture, $7.3 \%$ protein, $0.6 \%$ fat and $1.9 \%$ mineral matter. Total soluble solids content of pulp varies around 7.0, total acidity ranges between 3.0-2.3\% and pectin content between $3-5 \%$ (Pal, S.L. et al., 2018) ${ }^{[6]}$ which adds up to nearly 140 calories. The wood apple is rich in Beta carotene (Vijayakumar, et al., 2013) ${ }^{[10]}$. Wood apple fruit contains flavonoids, glycosides, saponins and tannins. There are reports that some coumarins and tyramine derivatives were also isolated from the fruits of Limonia (Ilango and Chitra, 2009) ${ }^{[4]}$. In India used as a liver and cardiac tonic, as an astringent means of halting diarrhea and dysentery and effective treatment for hiccough, sore throat and diseases of the gums. The pulp is poulticed onto bites and stings of venomous insects, as is the powdered rind. Intensive work on germplasm collection, evaluation and improvement was done on lasora, karonda and khejri which resulted in identification of some high yielding genotypes in these crops (Meghwal, 2018) ${ }^{[5]}$. There has been a growing interest world over to explore, search and collect germplasm of plants which could have economical viability in near future (Rapoport et al. 1995) ${ }^{[7]}$. 
Genetic diversity is maintained in traditional agro-ecosystems by cultural intervention as well as by natural selection. To safeguard the existing diversity of wood apple and to achieve sustainable development based on use of available genetic wealth, promotion and conservation is of immense importance. Azad et al., (2016) ${ }^{[1]}$ working on morphological diversity among accessions of cinnamon stated that the genetic diversity could be used for exploitation of economically important traits in the future a) Morphotaxonomic characterization of germplasms using Biodiversity International Tropical Fruit Descriptor and b) To perform preliminary evaluation of the varieties/types of under-utilized fruit crops for their productivity and nutritional quality.

\section{Materials and methods}

Different agroclimatic zones of West Bengal were stratified depending on availability of fruit crop and on convenience of the study. The study has been carried out in Bidhan Chandra Krishi Viswavidyalaya, Mohanpur, Nadia, West Bengal during the years 2013-2015.

Data for this study has been generated through key informant survey and individual household survey from respondents by using semi-structured questionnaire. In-situ characterization and preliminary evaluation of under-utilised/minor fruit Wood apple (Feronia sps.) are performed following Biodiversity International Tropical Fruit Descriptor.

The general information like age of the plant, behaviour of the plant was documented by making a questionnaire at the time of the survey. The genotypes were selected randomly with their varying age and location, which were further given accession numbers considering each accession as a treatment and replicating it for five times for all the quantitative parameters.

The analysis has been carried in three parts according to the variation in age of the plants and observations to be recorded. Under the observation for characterization, the plant physical parameters, physical and biochemical parameters of fruit were analyzed according to NBPGR tropical fruit descriptors. Multivariate analysis of characterization and evaluation parameters will be done following nearest neighborhood method of hierarchical clusters analysis of squared Euclidean distance matrix on the basis of characters measured following Dillon and Goldstein (1984).

\section{Result and Discussion}

Total 11 numbers of accessions were taken from different locations according to convenience of the study Table 1 . Branching pattern and crown shape was observed to be irregular in all the accessions whereas tree growth habit varied from erect to spreading type Table 2 . Leaf characters in wood apple revealed that obovate leaf blade shape, obtuse to retuse leaf apex, cuneate leaf base, odd pinnate leaf orientation and pinnate leaf venation Table 3. A report has been documented where age of the wood apple plants varied between 13 and 70 years with yield potential in mother plants (Ghosh et al. 2012) [3].

The proximity value 11.96 between ACC-3 and ACC-6 denoted maximum similarity among accessions for plant physical parameters followed by 14.64 between ACC-2 and ACC-5. The maximum value 4959.61 denoted minimum similarity between ACC-9 and ACC-10 Table 4. Out of twelve germplasm accessions of Lasora (Cordia myxa) it was noted that there was not much variation in different accessions with respect to vegetative growth such as plant height and canopy area but significant variation was recorded in fruit yield per plant and fruit characteristics (Meghwal, 2018) ${ }^{[5]}$.

Average linkage technique clustering when applied on squared Euclidean distance matrix a total of 6 clusters were formed for plant physical parameters. The data presented in the Table 5 and Fig. 1 showed that clusters 1 to 3 comprised of homogeneous types having similarity in characterization attributes. Cluster 4, 5 and 6 comprised of single member namely ACC-8, ACC-9 and ACC-7. ACC-3 and ACC-6 formed the first cluster at the distance of 11.96 followed by second cluster between ACC-2 and ACC-5 at 14.64. ACC-1 and ACC-4 combines in third stage at the distance 26.83 which later combines at the distance 42.30 with first cluster formed between ACC-3 and ACC-6.

Table 1: General experimental site details of Wood apple accessions

\begin{tabular}{|c|c|c|c|c|}
\hline $\begin{array}{c}\text { Accession } \\
\text { no. }\end{array}$ & Name of owner & Address & \multicolumn{2}{c|}{ Site of characterization } \\
\hline ACC-1 & Mintu Roy & Salugara (Jalpaiguri) & $26^{\circ} 74^{\prime} 88.54^{\prime \prime}$ & $088^{\circ} 43^{\prime} 82.91^{\prime \prime}$ \\
\hline ACC-2 & Shariful Mondal & Fatepur (Nadia) & $22^{\circ} 56^{\prime} 17.40^{\prime \prime}$ & $088^{\circ} 35^{\prime} 16.87^{\prime \prime}$ \\
\hline ACC-3 & Subhajeet Ghosh & Kanchrapara (North 24 paraganas) & $22^{\circ} 94^{\prime} 91.90^{\prime \prime}$ & $088^{\circ} 42^{\prime} 09.91^{\prime \prime}$ \\
\hline ACC-4 & Gulam Rahaman & Anantpore (North 24 paraganas) & $22^{\circ} 39^{\prime} 49.83^{\prime \prime}$ & $088^{\circ} 51^{\prime} 28.45^{\prime \prime}$ \\
\hline ACC-5 & B.C.K.V. & Mandouri farm (Nadia) & $22^{\circ} 56^{\prime} 51.09^{\prime \prime}$ & $088^{\circ} 31^{\prime} 1.58^{\prime \prime}$ \\
\hline ACC-6 & Masihar Rahaman & Anantpore (North 24 paraganas) & $22^{\circ} 39^{\prime} 49.83^{\prime \prime}$ & $088^{\circ} 51^{\prime} 28.45^{\prime \prime}$ \\
\hline ACC-7 & Chakka Tula Mondal & Anantpore (North 24 paraganas) & $22^{\circ} 39^{\prime} 49.83^{\prime \prime}$ & $088^{\circ} 51^{\prime} 28.45^{\prime \prime}$ \\
\hline ACC-8 & Kazi Abdul Gani & Fatepur (Nadia) & $22^{\circ} 56^{\prime} 17.40^{\prime \prime}$ & $088^{\circ} 35^{\prime} 16.87^{\prime \prime}$ \\
\hline ACC-9 & Arun Biswas & Baikara (Nadia) & $22^{\circ} 54^{\prime} 52.60^{\prime \prime}$ & $088^{\circ} 36^{\prime} 58.84^{\prime \prime}$ \\
\hline ACC-10 & Ashish koley & Haripal (Hoogly) & $22^{\circ} 86^{\prime} 77.69^{\prime \prime}$ & $088^{\circ} 36^{\prime} 76.32^{\prime \prime}$ \\
\hline ACC-11 & Sahuji Bandyopadyay & Canning (South 24 paraganas) & $22^{\circ} 31^{\prime} 12.58^{\prime \prime}$ & $088^{\circ} 65^{\prime} 79.42^{\prime \prime}$ \\
\hline
\end{tabular}

Table 2: General tree characteristics of Wood apple accessions

\begin{tabular}{|c|c|c|c|}
\hline Accession no. & Branching pattern & Tree growth habit & Crown shape \\
\hline ACC-1 & Irregular & Errect & Irregular \\
\hline ACC-2 & Irregular & Errect & Irregular \\
\hline ACC-3 & Irregular & Errect & Irregular \\
\hline ACC-4 & Irregular & Errect & Irregular \\
\hline ACC-6 & Irregular & Errect & Irregular \\
\hline
\end{tabular}




\begin{tabular}{|c|l|c|c|}
\hline ACC-7 & Irregular & Errect & Irregular \\
\hline ACC-8 & Irregular & Spreading \\
\hline ACC-9 & Irregular & Errect & Irregular \\
\hline ACC-10 & Irregular & Errect & Irregular \\
\hline ACC-11 & Irregular & Irregular \\
\hline
\end{tabular}

Table 3: Leaf characters of Wood apple accessions

\begin{tabular}{|c|c|c|c|c|c|}
\hline Accession no. & $\begin{array}{c}\text { Leaf blade } \\
\text { shape }\end{array}$ & Leaf apex shape & Leaf base shape & Leaf Orientation & Leaf Venation \\
\hline ACC-1 & Obovate & Obtuse-Retuse & Cuneate & Odd pinnate & Reticulate \\
\hline ACC-2 & Obovate & Obtuse-Retuse & Cuneate & Odd pinnate & Reticulate \\
\hline ACC-3 & Obovate & Obtuse Retuse & Cuneate & Odd pinnate & Reticulate \\
\hline ACC-4 & Obovate & Obtuse-Retuse & Cuneate & Odd pinnate & Reticulate \\
\hline ACC-5 & Obovate & Obtuse-Retuse & Cuneate & Odd pinnate & Reticulate \\
\hline ACC-6 & Obovate & Obtuse-Retuse & Cuneate & Odd pinnate & Reticulate \\
\hline ACC-7 & Obovate & Obtuse-Retuse & Cuneate & Odd pinnate & Reticulate \\
\hline ACC-8 & Obovate & Obtuse-Retuse & Cuneate & Odd pinnate & Reticulate \\
\hline ACC-9 & Obovate & Obtuse-Retuse & Cuneate & Odd pinnate & Reticulate \\
\hline ACC-10 & Obovate & Obtuse-Retuse & Cuneate & Odd pinnate & Reticulate \\
\hline ACC-11 & Obovate & Obtuse-Retuse & Cuneate & Odd pinnate & Reticulate \\
\hline
\end{tabular}

Table 4: Proximity Matrix for Wood apple plant physical attributes

\begin{tabular}{|c|c|c|c|c|c|c|c|c|c|c|}
\hline & \multicolumn{10}{|c|}{ Squared Euclidean Distance } \\
\hline & 1:ACC-1 & 2:ACC-2 & 3:ACC-3 & 4:ACC-4 & 5:ACC-5 & 6:ACC-6 & 7:ACC-7 & 8:ACC-8 & 9:ACC-9 & 10:ACC-10 \\
\hline 2:ACC-2 & 87.39 & & & & & & & & & \\
\hline $3: \mathrm{ACC}-3$ & 29.41 & 184.42 & & & & & & & & \\
\hline 4:ACC-4 & 26.83 & 94.19 & 24.58 & & & & & & & \\
\hline 5:ACC-5 & 52.22 & 14.64 & 109.15 & 41.09 & & & & & & \\
\hline 6:ACC-6 & 52.85 & 262.27 & 11.96 & 62.36 & 179.97 & & & & & \\
\hline 7:ACC-7 & 1052.42 & 565.93 & 1387.15 & 1112.48 & 746.36 & 1565.86 & & & & \\
\hline 8:ACC-8 & 2489.47 & 1685.60 & 2968.64 & 2522.65 & 1977.51 & 3224.50 & 332.14 & & & \\
\hline 9:ACC-9 & 3209.82 & 2305.45 & 3779.08 & 3316.38 & 2645.74 & 4076.01 & 592.79 & 146.12 & & \\
\hline 10:ACC-10 & 250.41 & 533.63 & 131.60 & 191.36 & 405.62 & 94.45 & 2129.02 & 3880.04 & 4959.61 & \\
\hline 11:ACC-11 & 204.79 & 383.42 & 124.39 & 125.47 & 286.01 & 115.34 & 1742.36 & 3279.54 & 4336.59 & 35.77 \\
\hline
\end{tabular}

This is a dissimilarity matrix

Table 5: Details of clusters for characterization variables using average linkage clustering methods on squared Euclidean distance matrix for Wood apple plant physical characters

\begin{tabular}{|c|c|}
\hline No. of clusters & Cluster members (Allowed distance co-efficient 42.30) \\
\hline 1 & Acc-3, Acc-6, Acc-1, Acc-4 \\
\hline 2 & Acc-2, Acc-5 \\
\hline 3 & Acc-10, Acc-11 \\
\hline 4 & Acc-8 \\
\hline 5 & Acc-9 \\
\hline 6 & Acc-7 \\
\hline
\end{tabular}

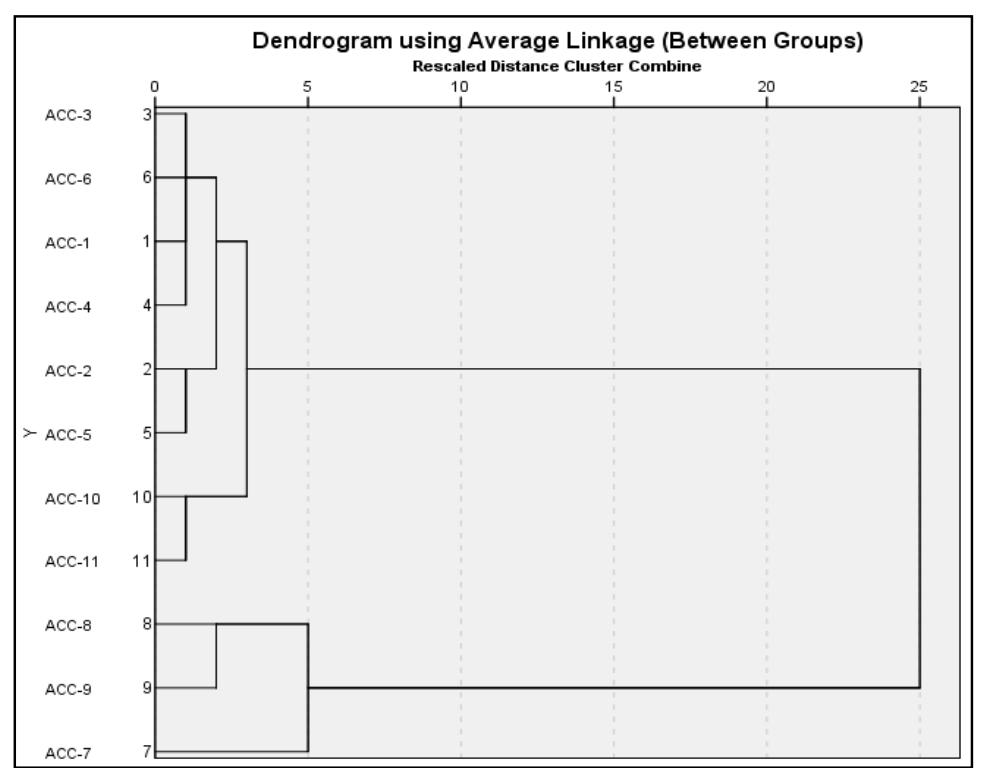

Fig. 1: Dendrogram using average linkage hierarchical clustering of squared Euclidean distance matrix for Wood apple plant physical attributes. 
The value 47.53 denoted maximum similarity between ACC-4 and ACC- 6 followed by 49.36 between ACC-7 and ACC-9 for fruit physical parameters. The maximum value 42812.52 between ACC-1 and ACC-8 denoted minimum similarity Table 6.

Average linkage technique clustering when applied on squared Euclidean distance matrix a total of 7 clusters were formed for fruit physical parameters. The data presented in the Table 7 and Fig. 2 shows that cluster 1, 3, 4 and 5 comprised of homogeneous types having similarity in characterization attributes. On the other hand cluster 2, 6 and 7 comprised single member namely ACC-8, ACC- 1 and ACC-2. The first cluster was formed in between ACC-4 and ACC-6 at the coefficient distance 47.53. The third cluster was formed in between ACC-3 and ACC-10 at the distance 87.41. Similarly, fourth cluster was formed between ACC-5 and ACC-11 at the distance 123.93 and fifth cluster comprised ACC-7 and ACC-9 paired at the distance 49.36.

ACC-7 and ACC-9 with minimum value 0.00 denoted the maximum similarity followed by 6.25 between ACC- 8 and ACC-9. The maximum value 3870.38 between ACC-1 and
ACC-8 denoted minimum accessions similarities for fruit biochemical parameters Table 8. The study of wood apple (Feronia limonia) in crop improvement programme showed great variability in physico-chemical characters among the 15 genotypes (Shete et al. 1999). Another work in improvement of some minor fruits through selection recorded fruit physical and chemical characteristics with much variability (Singh et al. 1999) ${ }^{[9]}$

Average linkage technique clustering when applied on squared Euclidean distance matrix a total of 6 clusters were formed for fruit biochemical parameters. The data presented in the Table 9 and Fig. 3 shows that cluster 1, 2 and 3 comprised of homogeneous types having similarity in characterization attributes. On the other hand cluster 4, 5 and 6 comprised single member namely ACC-4, ACC-1 and ACC-11. The first cluster comprised ACC-7, ACC-9, ACC-8 and $\mathrm{ACC}-10$ paired at the coefficient distance $0.00,6.26$ and 83.62. Second cluster was formed between ACC-5 and ACC6 at the coefficient distance 77.22. Likewise third cluster comprised ACC-2 and ACC-3 paired at the coefficient distance 97.36 respectively.

Table 6: Proximity matrix for Wood apple fruit physical attributes

\begin{tabular}{|c|c|c|c|c|c|c|c|c|c|c|}
\hline & \multicolumn{10}{|c|}{ Squared Euclidean Distance } \\
\hline & 1:ACC-1 & 2:ACC-2 & 3:ACC-3 & 4:ACC-4 & 5:ACC-5 & 6:ACC-6 & 7:ACC-7 & 8:ACC-8 & 9:ACC-9 & 10:ACC-10 \\
\hline 2:ACC-2 & 1305.92 & & & & & & & & & \\
\hline 3:ACC-3 & 9208.60 & 3673.77 & & & & & & & & \\
\hline 4:ACC-4 & 38765.07 & 26022.97 & 10189.98 & & & & & & & \\
\hline $5: A C C-5$ & 16888.61 & 8911.67 & 1159.30 & 4487.14 & & & & & & \\
\hline 6:ACC-6 & 38205.23 & 25604.69 & 9919.52 & 47.53 & 4314.06 & & & & & \\
\hline 7:ACC-7 & 615.54 & 626.71 & 6111.18 & 31785.12 & 12538.73 & 31401.62 & & & & \\
\hline 8:ACC-8 & 42812.52 & 29401.18 & 14142.53 & 3658.13 & 8286.24 & 4343.86 & 35922.13 & & & \\
\hline 9:ACC-9 & 724.90 & 808.63 & 6368.62 & 32171.20 & 12858.89 & 31828.26 & 49.36 & 36145.17 & & \\
\hline 10:ACC-10 & 9417.88 & 3768.03 & 87.41 & 10137.44 & 1165.17 & 9815.44 & 6575.62 & 13833.00 & 6897.46 & \\
\hline 11:ACC-11 & 16582.46 & 8750.40 & 1147.92 & 4762.01 & 123.93 & 4684.62 & 12025.82 & 8278.83 & 12207.34 & 1317.20 \\
\hline
\end{tabular}

This is a dissimilarity matrix

Table 7: Details of clusters for characterization variables using average linkage clustering methods on squared Euclidean distance matrix for Wood apple fruit physical characters.

\begin{tabular}{|c|c|}
\hline No. of clusters & Cluster members (Allowed distance co-efficient 123.93) \\
\hline 1 & Acc-4, Acc-6 \\
\hline 2 & Acc- 8 \\
\hline 3 & Acc-3, Acc-10 \\
\hline 4 & Acc-5, Acc-11 \\
\hline 5 & Acc-7, Acc- 9 \\
\hline 6 & Acc- 1 \\
\hline 7 & Acc- 2 \\
\hline
\end{tabular}

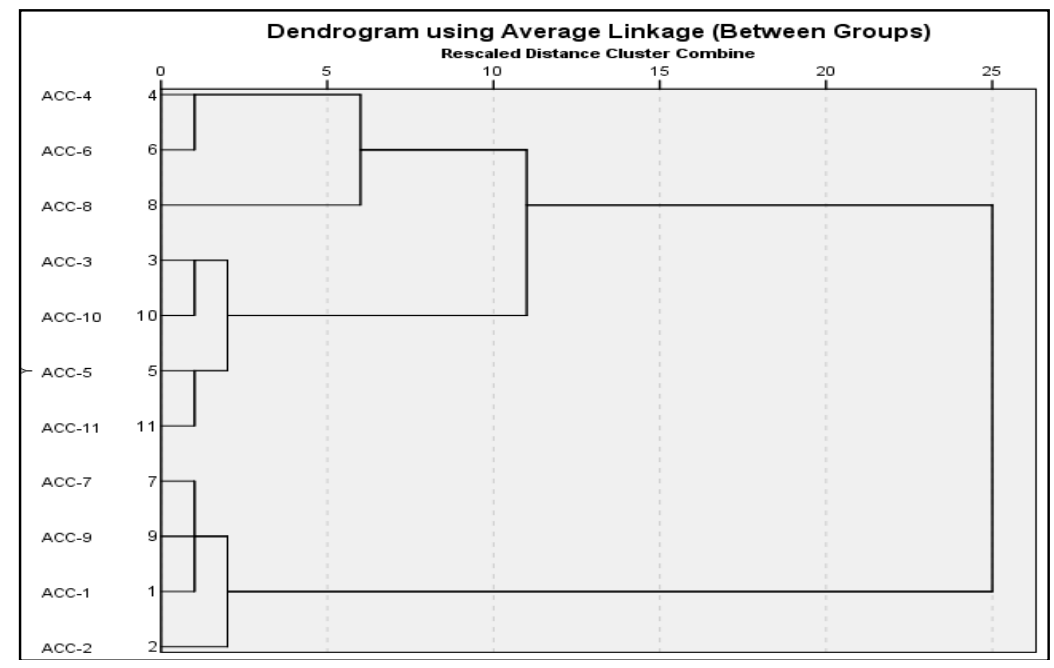

Fig 2: Dendrogram using average linkage hierarchical clustering of squared Euclidean distance matrix for Wood apple fruit physical characters. 1971 
Table 8: Proximity matrix for Wood apple fruit biochemical attributes

\begin{tabular}{|c|c|c|c|c|c|c|c|c|c|c|}
\hline & \multicolumn{10}{|c|}{ Squared Euclidean Distance } \\
\hline & 1:ACC-1 & 2:ACC-2 & 3:ACC-3 & 4:ACC-4 & 5:ACC-5 & 6:ACC-6 & 7:ACC-7 & 8:ACC-8 & 9:ACC-9 & 10:ACC-10 \\
\hline 2:ACC-2 & 1433.02 & & & & & & & & & \\
\hline 3:ACC-3 & 1833.26 & 97.36 & & & & & & & & \\
\hline $4: A C C-4$ & 1826.90 & 203.28 & 477.25 & & & & & & & \\
\hline $5: A C C-5$ & 3363.31 & 438.36 & 421.71 & 413.14 & & & & & & \\
\hline $6: \mathrm{ACC}-6$ & 2626.69 & 251.61 & 371.01 & 141.51 & 77.22 & & & & & \\
\hline 7:ACC-7 & 3596.53 & 545.65 & 472.36 & 652.73 & 108.17 & 262.43 & & & & \\
\hline 8:ACC-8 & 3870.38 & 652.65 & 544.67 & 772.29 & 133.34 & 330.32 & 6.25 & & & \\
\hline 9:ACC-9 & 3596.54 & 545.58 & 472.28 & 652.50 & 108.01 & 262.23 & .00 & 6.26 & & \\
\hline 10:ACC-10 & 3380.77 & 453.61 & 482.11 & 507.96 & 133.55 & 210.73 & 75.63 & 99.63 & 75.61 & \\
\hline 11:ACC-11 & 638.30 & 1008.95 & 1671.86 & 884.16 & 2291.31 & 1586.61 & 2522.32 & 2771.15 & 2522.32 & 2163.42 \\
\hline
\end{tabular}

This is a dissimilarity matrix

Table 9: Details of clusters for characterization variables using average linkage clustering methods on squared Euclidean distance mat rix for Wood apple fruit bio-chemical parameters.

\begin{tabular}{|c|c|}
\hline No. of clusters & Cluster members (Allowed distance co-efficient 97.36) \\
\hline 1 & Acc-7, Acc-9, Acc-8, Acc-10 \\
\hline 2 & Acc-5, Acc-6 \\
\hline 3 & Acc-2, Acc-3 \\
\hline 4 & Acc-4 \\
\hline 5 & Acc-1 \\
\hline 6 & Acc-11 \\
\hline
\end{tabular}

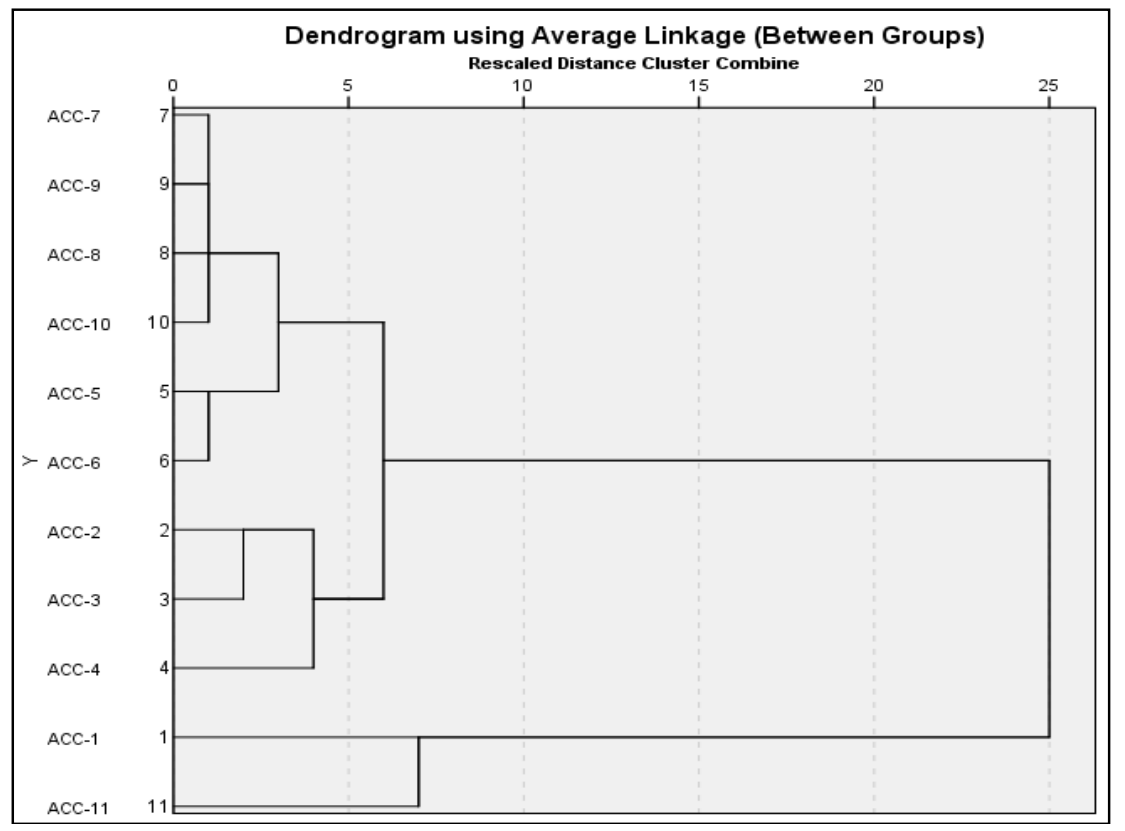

Fig. 3: Dendrogram using average linkage hierarchical clustering of squared Euclidean distance matrix for Wood apple fruit bio-chemical characters.

\section{Conclusion}

Branching pattern and crown shape was observed to be irregular in all the accessions whereas, tree growth habit varied from erect to spreading type. Leaf characters in wood apple reveals obovate leaf blade shape, obtuse to retuse leaf apex, cuneate leaf base, odd pinnate leaf orientation and pinnate leaf venation. During the course of survey the tree age of wood apple varied from $15 \mathrm{yrs}$ to above $40 \mathrm{yrs}$ in age at different germplasm. Height and trunk girth varied from $10 \mathrm{~m}$ to above $20 \mathrm{~m}$ and $88.2 \mathrm{~cm}$ to $157.4 \mathrm{~cm}$. Length of the leaf blade ranges from $3.05 \mathrm{~cm}$ to $4.12 \mathrm{~cm}$ and breadth varies from $1.06 \mathrm{~cm}$ to $3.08 \mathrm{~cm}$. Maximum fruit length was recorded in ACC-8 $(8.04 \mathrm{~cm})$ and breadth of $7.96 \mathrm{~cm}$ in ACC-6. Maximum fruit weight (306.02 g), peel weight (73.68 g) and number of seeds (28.42) was from the ACC-4. TSS ranged from $6.08^{\circ}$ Brix (ACC-1) to $15.12^{\circ}$ Brix (ACC-5). The present result is in partial conformity with the report of Ghosh et al. (2012) ${ }^{[3]}$ with fruit weight of wood apple between 130 to $225 \mathrm{~g}$, pulp percentage 42.9 to $60.6 \%$, T.S.S. range between 15 and $18.4^{\circ}$ brix and acidity 1.7 to $4.6 \%$. Maximum total sugar $28.57 \mathrm{mg} / 100$ gm pulp (ACC-1), reducing sugar $13.88 \mathrm{mg} / 100 \mathrm{gm}$ (ACC-4), acidity $1.77 \mathrm{mg} / 100 \mathrm{gm}$ (ACC-5) and Vit. C $102.04 \mathrm{mg} / 100 \mathrm{gm}$ (ACC-2) has been recorded. The pulp contains $18.1 \%$ carbohydrate, $7.1 \%$ protein, $3.7 \%$ fat, $5.0 \%$ fiber and $1.9 \%$ mineral matter. The pulp is a rich source of calcium, phosphorus, iron and vitamins like carotene, riboflavin, niacin, thiamine and vitamin $\mathrm{C}$ (Diengngan, S. and Hasan, M.A. 2015) ${ }^{[2]}$. Average linkage technique clustering when applied on squared Euclidean distance matrix a total of 6 clusters were formed for plant physical parameters, a total of 7 clusters were formed for fruit physical parameters and a total of 6 clusters were formed for fruit biochemical parameters. 


\section{References}

1. Azad R, Ranawaka RAAK, Senanayake G, Kumara KLW, Pushpakumara DKNG, Wijesinghe KGG et al. Morphological variation of cinnamon (Cinnamomum verum Persl) germplasm in Matara District of Sri Lanka. International Journal of Minor Fruits, Medicinal and Aromatic Plants. 2016; 2(1):6-14.

2. Diengngan S, Hasan MA. Genetic diversity of underutilized fruits in india for environmental sustainability. Advances in Plants \& Agriculture Research. 2015; 2(7):299-303.

3. Ghosh SN, Banik AK, Banik BC, Bera B, Roy S, Kundu A. Conservation, multiplication and utilization of wood apple (Feronia limonia) a semi-wild fruit crop in West Bengal (India). Acta Horticulturae, 2012; 948:279-283.

4. Ilango K, Chitra V. Antidiabetic and antioxidant activity of Limonia acdissimia linn. in alloxan induced rats. Der Pharmacia Lettre. 2009; 1:117-125.

5. Meghwal PR. Collection, evaluation and improvement of some underutilized fruits in hot Indian desert. Indian Journal of Arid Horticulture. 2018; 13(1-2):49-64.

6. Pal SL, Singh D, Attri PK. Evaluation of physicochemical properties of different types of pickles of wood apple (Limonia acidissima). Journal of Pharmacognosy and Phytochemistry. SP1, 2018, 1184-1187

7. Rapport EH, Raffaele E, Ghermandi L, Margutti L. Edible weeds: a scarcely used resource. Bulletin of Ecological Society of America. 1995; 76:163-166.

8. Shete MB, Karale AR, Kaulgud SN, More TA. Variability and correlation studies in wood apple. Journal of Maharashtra Agricultural Universities. 1999; 24(2):176-178.

9. Singh IS, Srivastava AZK, Singh V. Improvement of some under-utilised fruits through selection. Journal of applied Horticulture. 1999; 1(1):34-37.

10. Vijayakumar $\mathrm{P}$, Punitha K, Banupriya L. Drying characteristics and quality evaluation of wood apple (Limonia acidissima L.) fruit pulp powder. Int. J. Cur. Tr. Res. 2013; 2(1):147-150 